Jurnal Inovatif Ilmu Pendidikan Vol.1 No.2, (2019), HIm. 88- 100

http://jurnal.fkip.unila.ac.id/index.php/JIIP/index

JURNAL INOVATIF

Email : inovatif.ip@fkip.unila.ac.id

\title{
Studi Evaluatif Relevansi Model Pengembangan Kurikulum PGSD dengan Kurikulum SD di Bandar Lampung
}

\author{
Deviyanti Pangestu, Tegar Pambudhi, Maman Surahman \\ Pendidikan Guru Sekolah Dasar, Universitas Lampung
}

Jln. Prof. Dr. Soemantri Brojonegoro No. 1 Bandar Lampung 45145

E-mail: deviyanti.pangestu@ fkip.unila.ac.id

\section{Article Info \\ Received April 2019 \\ Accepted Agustus 2019 \\ Published Oktober 2019}

Keywords:

subject curriculum, integrated curriculum, Research and

Development

\begin{abstract}
The purpose of this study (1) to find out the relevance of the curriculum model development of Elementary School Teacher Education with the Elementary School curriculum, (2) to produce a level of improvement in courses that have relevance to the Elementary School curriculum, 3) produce textbooks. The method used in this study is Research and Development. Data collection used questionnaire and structured interview. The results showed that the average score of pedagogical competence of elementary school teachers was included in the excellent category. average score of professionalism of teachers included in the excellent category. The pedagogical abilities and professional abilities of teachers in relation to the relevance of the Elementary School Teacher Education curriculum with the curriculum in Primary Schools are included in the excellent category.
\end{abstract}

\begin{abstract}
Abstrak : Tujuan dari penelitian ini (1) untuk mengetahui relevansi pengembangan model kurikulum Pendidikan Guru Sekolah Dasar dengan kurikulum Sekolah Dasar, (2) untuk menghasilkan tingkat peningkatan dalam kursus yang memiliki relevansi dengan kurikulum sekolah dasar, (3) menghasilkan buku ajar. Metode yang digunakan dalam penelitian ini adalah Research and Development (R\&D). Pengumpulan data menggunakan kuesioner dan wawancara terstuktur. Hasil penelitian menunjukkan bahwa skor rata-rata kompetensi pedagogik guru Sekolah Dasar termasuk dalam kategori sangat baik. skor rata-rata Profesionalisme guru termasuk dalam kategori sangat baik. Kemampuan pedagogik dan kemampuan profesional guru dalam kaitannya dengan relevansi kurikulum Pendidikan Guru Sekolah Dasar dengan kurikulum di Sekolah Dasar termasuk dalam kategori sangat baik.
\end{abstract}

Kata kunci : Subject curriculum, integrated curriculum, Research and Development 


\section{PENDAHULUAN}

Peningkatan mutu pendidikan di Indonesia dilakukan melalui upaya peningkatan mutu guru secara berkesinambungan yang terrentang sejak masa pendidikan (pre-service) hingga sudah menjadi guru (in-service). Kebermutuan proses pendidikan guru menjadi upaya strategis dalam menyiapkan sumber daya manusia sebagai pelaku utama di era pesatnya perkembangan ilmu pengetahuan dan teknologi baik pada lingkup global maupun nasional. Sejumlah hasil penelitian membuktikan bahwa ada korelasi antara kompetensi guru tentang apa dan bagaimana siswa belajar dengan kondisi untuk belajar, dan keberhasilan guru dalam mengajar (Marton et al, 2014; Prosser \& Trigwell, 2008; Ramsden, 2012; Biggs, 2003). Indonesia merespon kondisi ini melalui kebijakan Undang-Undang Nomor 14 tahun Tahun 2005 tentang Guru dan Dosen yang secara langsung berimplikasi terhadap perlunya penyelarasan model, sistem, dan kurikulum pendidikan guru dengan kebutuhan stakeholders di lapangan.

Model pendidikan guru yang hanya merujuk pada salah satu konsep tanpa memperhatikan kebutuhan lapangan hanya akan menghasilkan produk yang mubadzir. Begitu juga sistem penyelenggaraan pendidikan yang hanya memperhatikan paradigma "input-proses-output" dalam membekali seperangkat kompetensi akan menimbulkan sejumlah kelemahan, sehingga model konsep kurikulum yang sudah lama dijadikan icon di pendidikan tinggi pun sudah saatnya ditinjau ulang kesesuaiannya dengan tuntutan perkembangan ilmu dan teknologi saat ini.

Kurikulum subjek akademik atau Separated subjek curriculum sebagai satu-satunya model kurikulum yang selama ini menjadi kiblatnya kurikulum Pendidikan Tinggi. Kurikulum ini bertumpu pada tujuan agar semua mahasiswa termasuk calon guru mampu menguasai kajian akademik secara mendalam. Calon guru SD dicetak untuk menguasai 1) sejumlah konten akademik (area of study) yang akan diajarkan di SD seperti; Matematika SD, IPA SD, Bahasa Indonesia SD, IPS SD, dan PPKn SD. 2) sejumlah kajian konten pedagogik sebagai sarana mengemas bahan-bahan kajian ke SD-an menjadi sebuah pembelajaran yang mendidik (pedagogical content knowledge). 
Di Pendidikan Tinggi, semua mahasiswa tidak terkecuali calon guru dituntut untuk menguasai bahan kajian secara mendalam dan parsial, tetapi manakala lulusan PGSD mengajar di SD, mereka dituntut agar mampu menggabungkan semua bahan kajian itu secara utuh dalam bentuk tematik terpadu, sesuai dengan tuntutan Permendikbud Nomor 67 Tahun 2013 tentang Kerangka dasar dan struktur kurikulum Sekolah Dasar/Madrasah Ibtidaiyah bahwa "Kurikulum 2013 untuk Sekolah Dasar didesain dengan menggunakan pembelajaran "tematik terpadu". Artinya guru dituntut untuk mengintegrasikan semua Mata pelajaran (Mapel) ke dalam suatu pembelajaran yang didasari oleh suatu tema.

Guru harus mampu menyuguhkan pembelajaran terpadu yang menggunakan tema untuk mengaitkan beberapa Mapel sehingga dapat memberikan pengalaman bermakna kepada sasaran didik. Landasan psikologis dari pembelajaran tematik terpadu adalah anak usia SD masih dalam rentangan berpikir integratif yaitu berpikir dari hal umum ke bagian demi bagian, mereka memandang sesuatu yang dipelajari sebagai suatu keutuhan (holistik), belum mampu memilahmilah konsep dari berbagai disiplin ilmu (Piaget, 1972).

Lebih lanjut Piaget menegaskan bahwa kemampuan berpikir anak usia SD masih pada level praoperasional dan terpadu, oleh karena itu pembelajaran bukan hanya diajarkan dengan menggunakan sistem guru kelas tetapi juga dikemas secara tematik terpadu. Ketika pembelajaran tidak tersekat-sekat antara satu Mapel dengan Mapel lainnya maka ketika itu pula terjadi proses pembelajaran yang melibatkan semua ranah sekaligus baik kognitif, afektif dan psikomotor. Kondisi psikologis tersebut menjadi landasan filosofis kurikulum 2013 SD.

Tuntutan kurikulum 2013 SD ini ternyata menimbulkan kesulitan pada guru dalam menyesuaikan paradigma berpikir mereka. Ketika mereka di Pendidikan Tinggi dirancang (by design) untuk menguasai kompetensi akademik secara parsial tetapi kurikulum 2013 SD menuntut guru untuk mengintegrasikannya secara tematik terpadu baik dalam merancang program, melaksanakan pembelajaran, dan mengevaluasinya.

Persoalan ini sesungguhnya menjadi suatu kewajaran karena selama ini kurikulum Pendidikan Tinggi yang digunakan untuk menyiapkan guru SD sama 
dengan kurikulum yang digunakan untuk menyiapkan calon guru Sekolah Menengah bahkan Pendidikan Tinggi yaitu menggunakan model kurikulum subjek akademik atau separated subject curriculum. Mereka dipersiapkan untuk menguasai bidang-bidang kajian secara mendalam dan terpisah antara satu bidang kajian dengan bidang kajian lainnya, tidak ada pendekatan khusus yang harus digunakan oleh dosen untuk menghubungkan mata kuliah yang diampunya dengan mata kuliah yang diampu oleh dosen lain, bahkan tidak ada mata kuliah khusus yang dikemas secara tematik untuk masuk ke semua mata kuliah secara terpadu.

Oleh karena itu menjadi suatu kewajaran pula manakala sosialisasi dan workshop kurikulum 2013 SD yang sudah dilakukan sejak awal tahun 2013 masih menyisakan kesulitan pada guru untuk mengembangkannya di lapangan. Pangkal persolalan dari masalah tersebut lebih didasari oleh kesulitan guru untuk merubah paradigma yang sudah dicetak sejak mereka dipersiapkan di Pendidikan Tinggi.

Penelitian ini bertujuan untuk mengnalisisrelevansi model kurikulum PGSD dengan Kurikulum SD secara rinci meliputi;

\section{Kurikulum SD}

1. Menganalisis persepsi guru SD tentang dimensi-dimensi kurikulum; a) ide, b) dokumen, c) implementasi, dan d) evaluasi.

2. Menganalisis tuntutan kebijakan model pengembangan kurikulum SD yang berkenaan dengan; a) Buku pedoman guru dan buku pedoman sasaran didik, b) Organisasi bahan ajar, c) Model Rencana Pelaksanaan Pembelajaran, d) Implementasi pembelajaran, e) Evaluasi pembelajaran.

\section{Kurikulum PGSD}

1. Menganalisis persepsi dosen tentang dimensi kurikulum ; a) ide, b) dokumen, c) implementasi, dan d) evaluasi.

2. Menganalisis kesesuaian keragaman content pedagogic yang disuguhkan dalam kurikulum PGSD dengan tuntutan penguasaan kompetensi pedagogik pengembang model kurikulum SD.

Salah satu indikasi keberhasilan kurikulum Pendidikan Tinggi (K-Dikti) yang dituntut oleh Permen riset, teknologi dan pendidikan tinggi nomor 44 tahun 
2015 yaitu harus berlandaskan pada acuan Kerangka Kualifikasi Nasional Indonesia (KKNI). Di dalam acuan itu outcomes K-Dikti yang dihasilkan harus memperhatikan scientific vision dan signal marget yang berkembang di masyarakat.

Kurikulum PGSD sesungguhnya sedang dipertaruhkan untuk dapat memenuhi tuntutan tersebut. Di dalam perkembangannya kurikulum PGSD yang berada pada jenjang Pendidikan Tinggi seyogyanya selalu bersesuaian dengan tuntutan profesionalisme pengembang kurikulum pada jenjang Pendidikan Dasar terutama SD, tetapi faktanya setiap terjadi penyempurnaan kurikulum SD yang sudah dimulai sejak kurikulum tahun 1975 sampai yang bersifat pembaharuan seperti kurikulum 2004 yaitu dimulainya pembelajaran tematik pada kelas awal SD hingga sekarang diberlakukan kurikulum SD 2013 ternyata tidak berbanding lurus dengan upaya penyempurnaan kurikulum PGSD.

Saat ini model kurikulum PGSD masih mengacu pada kurikulum subjek akademik atau separated subject curriculum, setiap dosen yang mengampu mata kuliah ke-SD-an memiliki dinding pemisah yang sangat kokoh, sehingga satu dengan yang lainnya hanya membahas bidang keilmuannya (body knowledge) masing-masing tanpa menyentuh bidang ilmu yang lain. Begitu juga dosen yang mengampu mata kuliah pedagogik, menjadikan kajian keilmuannya semakin konseptual alasannya bahwa untuk menjadi guru SD yang profesional, lulusan PGSD masih harus melanjutkan ke jenjang pendidikan profesi. Kondisi ini akan menimbulkan kesenjangan yang semakin lebar antara tuntutan profesionalisme pengembangan kurikulum di SD dengan upaya PGSD dalam menghasikan guru.

Pendidikan Guru Sekolah Dasar (PGSD) menjadi satu-satunya lembaga penghasil guru SD, baik pada level S1 maupun untuk pendidikan profesi jalur Pendidikan dan Latihan Profesi Guru (PLPG). Untuk itu hal utama yang harus diperhatikan dalam mengembangkan kurikulum program studi ini adalah mutlak harus mengikuti perkembangan kebutuhan stakeholders di lapangan, menyiapkan outcomes yang memiliki paradigma berpikir sesuai dengan tuntutan sekolah, bahkan ketika mereka mengikuti pendidikan profesi seyogyanya dipersiapkan agar memiliki kemudahan dalam beradaptasi baik berkenaan dengan mind set yang 
dimilikinya maupun mematangkan kemampuan praktisnya melalui sejumlah latihan yang sesuai dengan kebutuhan sekolah.

Kurikulum SD menegaskan tentang pentingnya filosofi model kurikulum humanistik yang memandang anak sebagai satu kesatuan kognisi, sosial, dan emosi. Kurikulum ini didasari oleh konsep pendidikan pribadi (persoznalized education) yang mengarahkan pendidikan untuk membina manusia secara utuh, artinya bukan saja dari segi fisik dan intelektual tetapi juga segi sosial dan afektif (emosi, sikap, perasaan, dan nilai) secara terpadu sebagai dasar pendidikan selanjutnya.

Tuntutan kebutuhan perkembangan anak usia SD ini semakin dikuatkan oleh pemberlakuan kurikulum tahun 2013 yang menekankan pendidikan secara konfluen dengan ciri-ciri utama 1) Partispasi; kurikulum ini menekankan partisipasi siswa dalam belajar. 2) Integrasi; adanya interaksi, interpenetrasi, dan integrasi dari pemikiran, perasaan dan juga tindakan. 3) Relevansi; adanya kesesuaian antara kebutuhan, minat dan kehidupan sasaran didik. 4) Pribadi anak; memberikan tempat utama pada pribadi anak untuk berkembang dan beraktualisasi potensi secara utuh. 5) Tujuan; memiliki tujuan mengembangkan pribadi yang utuh. 6) evaluasi; lebih mengutamakan proses dari pada hasil. Intinya sasaran pendidikan ini adalah perkembangan anak agar menjadi manusia yang lebih terbuka dan lebih mandiri. Muara dari konsep ini maka guru SD dituntut untuk mengemas kurikulum secara tematik terpadu baik dalam dimensi dokumen maupun implementasi, capaianhasilmaupun proses.

Keutamaan ini sekaligus menjadi ciri khusus kurikulum 2013 yang menjadikan Kompetensi Inti (KI) sebagai target dari standar kelulusan siswa dari suatu lembaga. Kompetensi Inti yang dimuat dalam kurikulum 2013 meliputi aspek sikap spiritual, sikap sosial, pengetahuan dan keterampilan. Sikap spiritual dan sikap sosial bersifat tidak diajarkan (indirect-teaching). Peran guru tidak cukup hanya sebagai sumber informasi tetapi guru juga harus menjadi model atau teladan yang akan ditiru secara langsung oleh sasaran didik-sasaran didiknya melalui perilaku pembiasaan. Dengan kata lain aspek pengetahuan dan keterampilan menjadi wahana pembentukan kepribadian anak secara utuh.

Guru harus mampu menyuguhkan pembelajaran terpadu yang menggunakan tema untuk mengaitkan beberapa Mapel sehingga dapat memberikan pengalaman 
bermakna kepada sasaran didik. Landasan psikologis dari pembelajaran tematik terpadu adalah anak usia SD masih dalam rentangan berpikir integratif yaitu berpikir dari hal umum ke bagian demi bagian, mereka memandang sesuatu yang dipelajari sebagai suatu keutuhan (holistik), belum mampu memilah-milah konsep dari berbagai disiplin ilmu (Piaget, 1972). Lebih lanjut Piaget menegaskan bahwa kemampuan berpikir anak usia SD masih pada level praoperasional dan terpadu, oleh karena itu pembelajaran bukan hanya diajarkan dengan menggunakan sistem guru kelas tetapi juga dikemas secara tematik terpadu. Ketika pembelajaran tidak tersekat-sekat antara satu Mapel dengan Mapel lainnya maka ketika itu pula terjadi proses pembelajaran yang melibatkan semua ranah sekaligus baik kognitif, afektif dan psikomotor. Kondisi psikologis tersebut menjadi landasan filosofis kurikulum tahun2013 SD.

Kesiapan guru SD sangat dipengaruhi oleh keberadaan LPTK sebagai lembaga penghasil calon guru. Kurikulum yang digunakan oleh LPTK harus bersesuaian dengan tuntutan profesionalisme pengembang kurikulum SD. Klimaks profesionalisme guru SD bukan hanya pada penguasaan bidang kajian ke-SD-an secara mendalam dan parsial tetapi bagaimana mengemas bidang yang parsial itu menjadi terpadu dalam suatu pembelajaran. Hammond (2005) menegaskan bahwa " ...develop teachers who can act on their commitments, who are highly knowledgeable about learning and teaching and who have strong practical skills " Hamond menegaskan bahwa lembaga pendidikan guru sangat penting mengembangkanguru yangdapatbertindak ataskomitmen mereka, yangsangatberpengetahuan tentangbelajar dan mengajardan yang memilikiketerampilan praktisyang kuat.

Struktur kurikulum PGSD harus mampu menyandingkan model kurikulum humanistik SD dengan kurikulum subjek akademik Pendidikan Tinggi. Kedua model kurikulum ini harus dicari irisannya untuk dikuatkan di kurikulum PGSD. Bagian yang beririsan ini harus dirancang menjadi kajian Content Subject Academic (CSA) ke-SD-an yang berorientasi pada pengembangan aspek kompetensi akademik sebagai praktisi pendidikan dan akademisi ke-SD-an, sedangkan yang tidak beririsan menjadi muatan Content Specific Pedagogy (CSP) yang bisa dibangun menjadi suatu kajian akademik khusus tentang profesi pengembang 
kurikulum SD atau menjadi suatu pendekatan yang digunakan oleh semua dosen dalam merancang, melaksanakan dan mengevaluasi kajian content academic keSD-an. Dengan demikian kompetensi yang dikembangkan dari calon guru akan mendekatkan kemampuan untuk beradaptasi dengan tuntutan di lapangan.

Dua jenis kurikulum yaitu kurikulum humanistik dan kurikulum subjek akademik yang saling beririsan dan menjadi dasar pengembangan kurikulum program studi PGSD. Walaupun PGSD berada pada jenjang Pendidikan Tinggi yang selama ini menggunakan model kurikulum subjek akademik dengan orientasi untuk menghasilkan outcomes yang menguasai keilmuan secara mendalam, tetapi tidak dapat dipungkiri bahwa lulusan yang akan dihasilkan juga harus mampu beradaptasi dengan model kurikulum humanistik yang menjadi dasar pengembangan kurikulum SD. Pandangan terhadap profesionalisasi guru memiliki pengaruh terhadap elemen-elemen yang dipandang penting pada kurikulum pendidikan guru. Fokus ini bisa pada interaksi dosen-mahasiswa, content academic, bahkan berkontribusi terhadap pengembangan sekolah, atau hubungan guru dengan masyarakat sekitar (Martin \& Marsh, 2008).

Suatu hal yang tidak dapat dikesampingkan oleh LPTK adalah bagaimana mendesain kurikulum yang dapat membentuk paradigma calon guru agar memiliki kemampuan untuk beradaptasi dengan tuntutan lapangan. Berikut ini beberapa hal yang dianjurkan oleh Martin dan Loomis (2007) “... prior knowledge and experiences to help establish, obtain new information and experiences from the text, class work, fieldwork, and other sources, combining prior knowledge with the new information and experiences". Mendesain pengetahuan, pengalaman, dan peluang untuk menghadapi tantangan menjadi sama pentingnya bagi kurikulum LPTK dalam rangka mempersiapkan outcomes yang memiliki kemampuan beradaptasi dengan tuntutan profesionalisme di lapangan.

Kurikulum subjek akademik menjadi satu-satunya model kurikulum di Pendidikan Tinggi. Kurikulum ini bersumber dari pendidikan klasik yang didasari oleh faham peresialisme dan esensialisme. Faham ini berasumsi bahwa semua ilmu pengetahuan dan nilai sudah ditemukan oleh para ahlinya pada masa lalu. Oleh karena itu fungsi pendidikan adalah harus memelihara dan mewariskannya. Orang yang berhasil dalam belajar adalah yang menguasai seluruh atau sebagian besar isi 
pendidikan itu dengan kata lain aspek intelektual yang paling diutamakan dalam kurikulum ini. Kurikulum ini lebih mengutamakan isi pendidikan yang diambil dari setiap disiplin ilmu. Guru sebagai penyampai bahan ajar mempunyai peranan penting, yaitu menguasai semua pengetahuan yang ada dalam kurikulum dan menjadi ahli dalam bidang-bidang studi yang diajarkan.

Kurikulum subjek akademik mempunyai beberapa ciri berkenaan dengan tujuan, metode, organisasi isi, dan evaluasi. Tujuan dari kurikulum subjek akademis adalah pemberian pengetahuan yang solid serta melatih para siswa menggunakan ide-ide dan proses "penelitian". Siswa diharapkan memiliki konsep-konsep dan cara-cara yang dapat dikembangkan dalam masyarakat yang lebih luas. Metode yang paling banyak digunakan dalam kurikulum ini adalah metode ekspositori. Ideide dari guru dielaborasi oleh siswa sehingga dapat dikuasai. Isi atau konten sudah terstruktur dalam buku-buku tekstual, dan sasaran evaluasinya adalah untuk mengetahui sejauhmana penguasaan konsep-konsep itu tercapai. Model kurikulum ini digunakan oleh jenjang Pendidikan Tinggi karena berorientasi untuk menghasilkan ahli suatu bidang tertentu.

Struktur keilmuan di Pendidikan Tinggi sudah sangat fixed, fokus, dan khusus. Di dalamnya mahasiswa hanya akan menguasai keilmuan yang menjadi pilihannya. Setiap ilmu tidak lagi dikembangkan untuk terhubung dengan ilmu yang lainnya walaupun berada dalam satu rumpun, karena masing-masing fokus pada body knowledge yang menjadi ciri khusus dari ilmu itu sendiri. Organisasi kurikulum ini dirancang dengan tujuan agar setiap mahasiswa mampu menguasai secara mendalam dan utuh setiap bidang kajian yang diminatinya, self-actualized, self-derected, proses persiapan karir, dan mengembangkan kemampuan berpikir kritis.

Orientasi kurikulum subjek akademik sebagai ciri khas model kurikulum jenjang Pendidikan Tinggi sangat berbeda dari kurikulum humanistik yang digunakan oleh SD. Kurikulum humanistik didasari oleh konsep aliran pendidikan pribadi (personalized education), John Dewey (Progressive Education) dan J.J. Rousseau (Romantic Education). Aliran ini lebih memberikan tempat pada siswa dan memandang siswa sebagai subjek yang menjadi pusat kegiatan pendidikan. Ada 
beberapa aliran yang termasuk dalam pendidikan humanistik, diantaranya yaitu pendidikan konfluen.

Kedua kurikulum (subjek akademik dan humanistik) menjadi dasar pengembangan kurikulum PGSD. Di satu sisi tidak dapat dipungkiri karena PGSD berada pada jenjang Pendidikan Tinggi harus menggunakan model kurikulum subjek akademik agar lulusannya menguasai suatu bidang keilmuannya secara utuh, tetapi yang sama pentingnya adalah stakeholders yang menggunakan keahliannya menuntut profesionalisme pengembang kurikulum humanistik.

Kondisi ini menuntut PGSD untuk me-redesign kurikulumnya agar menyandingkan kedua model kurikulum di atas ke dalam struktur yang harmonis sehingga tidak kehilangan subjek akademiknya dalam rangka menyiapkan lulusan yang menguasai bidang ke-SD-an, tetapi kental dengan humanistiknya yang akan menjadi iklim pembelajaran di SD. Desain kurikulum PGSD ini harus merujuk pada pembelajaran yang menekankan content academic based dan content-specific pedagogy. Prinsip ini melandasi re-design kurikulum PGSD yang mengarah pada pengembangan PGSD dan kepentingan SD sekaligus.

Kurikulum PGSD yang berelevansi dengan kurikulum SD menjadi model kurikulum yang tidak akan mengurangi orientasi kurikulum subjek akademik, karena dengan penguasaan bidang ke-SD-an secara utuh dapat memudahkan guru untuk memadukan semua Mata Pelajaran (Mapel) ke dalam pembelajaran tematik terpadu di SD dan penguasaan pedagogi akan dapat mempermudah mengemas pembelajaran menjadi tidak kaku, untuk itu perlu dibangun core centra suatu mata kuliah dan melihat keterhubungan antar Mata Kuliah yang dapat memudahkan terbentukanya paradigma mahasiswa ketika menjadi pengembang kurikulum di SD. Desain kurikulum PGSD yang berelevansi dengan kurikulum SD ini memadukan berbagai konten akademik ke-SD-an melalui penguasaan konten pedagogik sebagai tuntutan pembelajaran yang efektif dan memberikan kesempatan untuk mengembangkan prinsip-prinsip pedagogik dalam praktik pembelajaran di sekolah

\section{METODE}

Penelitian menggunakan pendekatan R\&D (Research and Development) dengan objek penelitian adalah Kurikulum PGSD berelevansi dengan kurikulum 
SD. Model pengembangan akan diarahkan pada penyusunan kurikulum PGSD yang berelevansi dengan kurikulum SD.

\section{HASIL DAN PEMBAHASAN}

Berdasarkan data hasil penelitian, didapatkan skor rata-rata kompetensi pedagogi guru SD pada aspek pemahaman terhadap peserta didik, desain pembelajaran, melaksanakan pembelajaran sesuai dengan indikator, dan melaksanakan evaluasi.

Pemahaman guru terhadap peserta didik dalam relevandi kurikulum PGSD dengan kurikulum di SD masuk dalam kategori sangat baik dengan skor 111 . Desain pembelajaran juga merupakan salah satu aspek yang memiliki skor 109 dengan katergori sangat baik. Aspek melaksanakan pembelajaran sesuai dengan indikator juga guru rata-rata telah melaksanakan dengan sangat baik dengan skor 109. Lalu kemudian, dalam melaksanakan pembelajaran guru juga telah melaksanakan evaluasi dengan kategori sangat baik dengan skor 107.

Dari hasil analisis keprofesionalan guru, penguasaan bidang keilmuan konten akademik mapel ke-SD-an yang mencakup mapel matematika, IPA, IPS, PKn dan Bahasa Indonesia masuk dalam kategori sangat baik dengan skor total 520. Penguasaan struktur dan metode keilmuan yang mencakup mapel matematika, IPA, IPS, PKn dan Bahasa Indonesia masuk dalam kategori sangat baik dengan skor total 510.

Berdasarkan data hasil penelitian, pemahaman guru terhadap peserta didik dalam relevansi kurikulum PGSD dengan kurikulum di SD masuk dalam kategori sangat baik. Desain pembelajaran juga merupakan salah satu aspek yang memiliki skor dengan katergori sangat baik. Aspek melaksanakan pembelajaran sesuai dengan indikator juga guru rata-rata telah melaksanakan dengan sangat baik. Lalu kemudian, dalam melaksanakan pembelajaran guru juga telah melaksanakan evaluasi dengan kategori sangat baik.

Dari hasil analisis data di atas dapat kita simpulkan sebagai berikut. Penguasaan bidang keilmuan konten akademik mapel ke-SD-an yang mencakup mapel matematika, IPA, IPS, PKn dan Bahasa Indonesia masuk dalam kategori sangat baik. Penguasaan struktur dan metode keilmuan yang mencakup mapel 
matematika, IPA, IPS, PKn dan Bahasa Indonesia masuk dalam kategori sangat baik. Secara keseluruhan, kemampuan pedagogik dan kemampuan profesional guru dalam kaitannya dalam relevansi kurikulum PGSD dengan kurikum di SD memiliki keterkaitan dalam kategori sangat baik.

\section{KESIMPULAN}

Berdasarkan pembahasan yang telah diuraikan, maka dapat disimpulkan sebagai berikut.

1. Pemahaman guru terhadap peserta didik dalam relevansi kurikulum PGSD dengan kurikulum di SD masuk dalam kategori sangat baik.

2. Desain pembelajaran juga merupakan salah satu aspek yang memiliki skor dengan katergori sangat baik.

3. Aspek melaksanakan pembelajaran sesuai dengan indikator juga guru rata-rata telah melaksanakan dengan sangat baik.

4. Pada saat melaksanakan pembelajaran guru juga telah melaksanakan evaluasi dengan kategori sangat baik.

5. Penguasaan bidang keilmuan konten akademik mapel ke-SD-an yang mencakup mapel matematika, IPA, IPS, PKn dan Bahasa Indonesia masuk dalam kategori sangat baik.

6. Penguasaan struktur dan metode keilmuan yang mencakup mapel matematika, IPA, IPS, PKn dan Bahasa Indonesia masuk dalam kategori sangat baik.

\section{DAFTAR PUSTAKA}

Biggs, J.B. (2003). Teaching for Quality Learning at University, 2nd Ed., The Society for Research into Higher Education \& Open University Press, Buckingham.

Martin, A. J., \& Marsh, H. W. (2008). Academic buoyancy: Towards an understanding of students' everyday academic resilience. Journal of school psychology, 46(1), 53-83.

Martin, D. J., \& Loomis, K. S. (2013). Building teachers: A constructivist approach to introducing education. Cengage Learning. 
Marton, F., \& Saljo, R. (2014). Approaches to learning. The experience of learning. Implications for teaching and studying in higher education (pp. 39-58). Edinburgh: Scottish Academic Press.

Permendikbud Nomor 67 Tahun 2013 tentang Kerangka dasar dan struktur kurikulum Sekolah Dasar/Madrasah Ibtidaiyah.

Permendikbud. Nomor 160 tahun 2014 pasal 4 tentang pemberlakuan kurikulum 2006 dan kurikulum 2013.

Permenristekdikti Nomor 44 Tahun 2015 tentang Standar Nasional Pendidikan Tinggi

Piaget, J. (1972). The child and reality, problems of genetic psychology. New York: Penguin Books.

Prosser, M. and Trigwell, K, (2008). Teaching for learning in higher education.

Ramsden, P. (2012), Learning to Teach in Higher Education. London:Routledge.

Undang-Undang No 14 Tahun 2005 tentang Guru dan Dosen. 